\title{
La modernidad y el humanismo jesuita del siglo XVII: la influencia de John Locke en el tratamiento de la justicia de Francisco Javier Alegre
}

\author{
Hugo Rolando Aquino Cruz
}

\section{Introducción}

Y a he hecho algún ensayo de cómo podría presentarse esta investigación. En aquel primer esbozo atendía a las similitudes entre las argumentaciones de Francisco Javier Alegre y Locke; en esta ocasión quiero complementar aquel trabajo profundizando en las similitudes estructurales entre ambos pensadores.

Con la intención de explorar el pensamiento de Francisco Javier Alegre me propongo sugerir algunas de las influencias que detecto en su noción de justicia -con especial atención a su tratamiento de la justicia distributiva. No sin antes hacer una breve síntesis de la situación de los jesuitas en su época y exhibir, con ello, el modo en que Alegre entra dentro de ese esquema.

Expondré el tratamiento de Alegre de la justicia en Instituciones teológicas con base en el libro VI, proposición XIX, titulado: "Acerca de los vicios opuestos a la justicia". Allí exhibiré el modo en que, echando mano del lenguaje escolástico, Alegre empata con ciertas nociones del Ensayo del gobierno civil de John Locke. Para ello analizaré algunas nociones del pensamiento lockeano, particularmente la de propiedad que me parece se encuentra implícita en el pensamiento de Alegre.

\section{Los jesuitas del siglo XVIII: Francisco Javier Alegre}

\section{Los jesuitas novohispanos y Europa}

Es importante empezar con un breve relato de la situación de los jesuitas en el siglo XVIII para contextualizar el trabajo de Francisco Javier Alegre. La producción de estos intelectuales está fuertemente influida por su tensa situación frente a la Corona española: 
En la madrugada del 25 de junio de 1767 la Compañía de Jesús fue expulsada de la Nueva España de acuerdo con la Real Pragmática de Carlos III, expedida unos meses antes. Este acontecimiento fue de gran trascendencia para México, no sólo desde el punto de vista político y económico sino también intelectual, ya que esa arbitraria disposición del monarca eliminó de golpe a la que era el soporte de la cultura criolla novohispana, a la vez que cortó una vigorosa corriente intelectual moderna -científica, filosófica e histórica-impulsada por los jesuitas. ${ }^{1}$

¿En qué consistía esta corriente intelectual? ¿Cuáles eran sus notas principales? En este contexto de pugna social se termina por definir lo que Rovira llama el "eclecticismo" jesuita. Rovira, utilizando a Clavijero -contemporáneo de Alegre- como ejemplo lo explica de este modo: "Clavijero [...] con suma prudencia se abre a la modernidad [...] Su pensamiento filosófico se caracteriza por un cierto eclecticismo, esto es, intenta a veces conciliar las innovaciones de la filosofía y ciencia con el tradicionalismo de la filosofía escolástica [...]"2

Esta actitud "ecléctica" no debe entenderse como una falta de principios o adhesión a ciertas convicciones, por el contrario, será el recurso a las nuevas propuestas para tener una nueva perspectiva sobre la tradición.

Es necesario advertir que juzgamos al eclecticismo que se da en el siglo XVIII en los países de lengua española y portuguesa como un movimiento filosófico necesario, dadas las tensiones existentes. El eclecticismo intenta una conciliación entre la modernidad y la tradición. Por lo mismo, en cierto modo presenta una originalidad en el tratamiento y enfoque de ciertos problemas; por ello mismo, si no fue creador fue vivificador, remozador frente a un tradicionalismo religioso y filosófico [... $]^{3}$

${ }^{1}$ Elías Trabulse, "Clavigero, historiador de la Ilustración mexicana", en Alfonso Martínez Rosales, comp., Francisco Xavier Clavigero en la Ilustración mexicana 1731-1787. Alicante, Biblioteca Virtual Miguel de Cervantes, 2009. Versión electrónica en: www.cervantesvirtual.com/obra-visor/francisco-xavier-clavigero-en-la-ilustracinmexicana-17311787-0/html/0210e984-82b2-11df-acc7-002185ce6064.html, \& II. [Consulta: 10 de octubre de 2014 .]

${ }^{2}$ María del Carmen Rovira Gaspar, "Filosofía y humanismo", en M. del C. Rovira Gaspar y Carolina Ponce Hernández, comps., Antología: Instituciones teológicas, de Francisco Javier Alegre. Ejercitaciones arquitectónicas $y$ Dos antiguos monumentos de arquitectura mexicana, de Pedro Márquez. Trad. de Mauricio Beuchot, Carolina Ponce, María Leticia López y José Luis Bernal. México, unAm, Facultad de Filosofía y Letras, 2007, p. 45.

${ }^{3}$ Ibid., p. 45, n. 19. 
Historiadores como Alfonso Alfaro han dado testimonio de este espíritu en el mundo jesuita:

Eran capaces de "montarse" al hebreo y al griego; eran capaces de tener información de China, de la India, de Flandes, de Bohemia, de Estados Unidos, y de comunicar todo eso en náhuatl y en pápago y en la tarahumara. Ésa era la élite del país: una élite con contactos con el mundo, con su pasado, con la modernidad tecnológica y con la raíz más profunda del país $[\ldots]^{4}$

Estas capacidades desarrolladas por la Compañía de Jesús, que se manejaba como una red internacional de información y de intercambio cultural, son lo que Torales Pacheco llama el carácter cosmopolita de los jesuitas del siglo XVIII: "Es probado el carácter cosmopolita de los jesuitas novohispanos durante el siglo XVIII. La Compañía de Jesús era universal en su composición y en la proyección de sus objetivos, lo cual propiciaba la constante movilidad de sus miembros [...]"5

Esta movilidad proveyó de un carácter multicultural al pensamiento jesuita. Se convirtieron en auténticos intelectuales interculturales, capaces de emplear información de diversas fuentes y sintetizarla en función de propósitos prácticos: "[...] la Compañía es un ejemplo de interculturalidad, entre otras cuestiones, porque en su estructura y su quehacer cotidianos, operaron de manera natural los intercambios intelectuales entre Europa, América y Asia aun allende las fronteras del mundo hispánico". ${ }^{6}$

El intercambio de información de los jesuitas no sólo fungió como un modo para que éstos se hicieran partícipes de lo que sucedía en la Europa moderna, sino que también sirvió como medio para que dieran a conocer las características del mundo americano:

Reconocida por los jesuitas la importancia del conocimiento del espacio y la naturaleza de América y de Asia como un medio para el logro de su programa pastoral, el estudio de los pueblos, de la geografía y

${ }^{4}$ Alonso Alfaro, "Los jesuitas no pueden llamarse precursores de la Independencia, pero sí constructores de la nación, que es mucho más importante". Entrevista (entrevistador: Enrique González), Red Juvenil Ignaciana: www.redjuvenilignaciana.org/ documentos/independencia/2.doc, p. 1. [Consulta: 10 de octubre de 2014.]

${ }_{5}$ María Cristina Torales Pacheco, "Apuntes para el estudio de la presencia de la Ilustración alemana en México", en Jahrbuch für Geschichte Lateinamerikas, núm. 40, 2003, p. 125.

${ }^{6}$ M. C. Torales Pacheco, "Los jesuitas y la independencia de México: algunas aproximaciones", en Destiempos, año 3, núm. 14, marzo-abril, 2008, p. 400. Versión electrónica en www.destiempos.com/n14/torales.pdf. [Consulta: 10 de octubre de 2014.] 
de las propiedades naturales de América y de Asia representaron un reto para todos ellos. Diarios, mapas, textos, producto de sus exploraciones conformaron un saber corporativo. Las crónicas e historias que la Compañía de Jesús publicó sobre la Nueva España, aparecieron firmadas por un autor, pero sus contenidos pasaban a formar parte de la suma de los conocimientos de sus miembros. ${ }^{7}$

A esta comunidad intelectual nutrida por un vivo intercambio cultural habría que sumar un profundo cariño por las tierras americanas. Ya en el exilio, los jesuitas se dedicaron a dar testimonio de la Nueva España, y no sólo eso, sino también a oponerse a aquellos que hablaban en detrimento de la misma.

[...] otra de las características de este grupo de jesuitas mexicanos innovadores [...] su recuerdo de México, la patria lejana, hacia la que guardaron siempre un gran cariño y fidelidad; procurando, por medio de sus obras, que se conociera en Europa [...] la cultura mexicana, defendiéndola de los ataques y críticas que sobre ella habían lanzado algunos europeos. ${ }^{8}$

Una vez más Clavijero se muestra como un interesante ejemplo a este respecto como señala Dorothy Tanck:

Con una perspectiva balanceada -no siempre una característica de los historiadores del autollamado "siglo de las luces", que tendían a sobreevaluar todo lo europeo- Clavijero advertía de las implicaciones que pudieran tener las teorías que exaltaban un continente, una cultura, una raza, arriba de otros pueblos, que despreciaban y calumniaban culturas y razas diferentes. ${ }^{9}$

Con esta perspectiva, Clavijero no sólo está mostrando su apertura a lo distinto, sino también un arraigo y aprecio a las culturas americanas. Este orgullo por lo novohispano, por lo mexicano, no era ajeno a otros jesuitas,

${ }^{7}$ Ibid., p. 402.

${ }^{8}$ M. del C. Rovira Gaspar, "Filosofía y humanismo", en op. cit., p. 50.

${ }^{9}$ Dorothy Tanck, "Clavigero: defensor de los idiomas indígenas frente al desprecio europeo", en Alfonso Martínez Rosales, comp., Francisco Xavier Clavigero en la Ilustración mexicana 1731-1787. Alicante, Biblioteca Virtual Miguel de Cervantes, 2009. Versión electrónica en: www.cervantesvirtual.com/obra-visor/francisco-xavier-clavigeroen-la-ilustracin-mexicana-17311787-0/html/0210e984-82b2-11df-acc7-002185ce6064. html, $\mathbb{f}$ "El tema de las lenguas indígenas en la historia antigua". [Consulta: 10 de octubre de 2014.] 
era una especie de validación del trabajo que se llevaba a cabo de este lado del Atlántico:

Una parte muy hermosa y enternecedora y ahora difícilmente valorable de su aportación (de todos los jesuitas), consiste en los textos que escriben en latín y las traducciones del griego al latín, así como los textos literarios en español. Tratan de decirle a Europa: "Miren de lo que somos capaces. Si se considera que un pueblo es digno de admiración o de respeto por la envergadura de su producción literaria y científica, vean lo que somos capaces de hacer: nuestro latín no es inferior al de ustedes, nuestro conocimiento de las culturas clásicas no es inferior al de ustedes". ${ }^{10}$

\section{Un nuevo sistema del mundo}

Esta revolución en el modo de acceder a las fuentes antiguas y a la tradición misma tuvo en la física y la astrología uno de sus principales asideros, acaso el más determinante, pues es gracias a esta nueva concepción del mundo físico que se rompe un sistema del mundo tradicional y se da paso - en la medida que se consideraba prudente- al nuevo sistema del mundo. "Animados por un ideario pedagógico semejante, que ya revela un tipo de preocupación típicamente ilustrada, algunos hombres de ciencia, fueran religiosos o laicos, emprendieron, al principio con bastante timidez, la reforma de los estudios astronómicos en México y plantearon la posibilidad de enseñar un nuevo 'sistema del mundo'". ${ }^{11}$

Esta apertura a una nueva concepción del mundo no significaba un rechazo a la tradición, más bien significó un nuevo modo de estudio que permitió la entrada de nuevas ideas que terminarían por ayudar a reevaluar aquella tradición:

[...] la cosmología de los pensadores jesuitas novohispanos del siglo ilustrado cierra un ciclo completo que va de las teorías geocéntricas ptolemaicas a la tesis de la pluralidad de los mundos habitados en un cosmos newtoniano. Singular evolución que nos permite comprender la forma en que los miembros de la Compañía de Jesús pudieron abrirse y aceptar las nuevas teorías científicas del siglo XVIII, sin que por ello tuvieran que sacrificar la ortodoxia de sus creencias religiosas. ${ }^{12}$

${ }^{10}$ A. Alfaro, "Los jesuitas no pueden llamarse precursores de la Independencia, pero sí constructores de la nación, que es mucho más importante", pp. 2-3.

${ }^{11}$ E. Trabulse, "Cosmología de los jesuitas novohispanos", en Artes de México, núm. 82, 1966, p. 43.

${ }^{12}$ Ibid., p. 45. 
Tanto Clavijero -considerado por muchos el principal referente de los jesuitas de este siglo- como Alegre son ejemplos de esta apertura a la ciencia moderna y, a la vez, ejemplos de este arraigo -y reevaluación- a la tradición:

[...] Alegre, Clavijero [...] Del primero sabemos que en la sección de su Cursus philosophicus consagrada a estos temas, trató y al parecer enmendó, suponemos que para aceptarla, la teoría cosmológica de Tycho Brahe. En cuanto al padre Clavijero, de quien poseemos el más largo testimonio sobre el asunto contenido en su Physica particularis, diremos que dedicó varias páginas a exponer y discutir el sistema copernicano y a rechazarlo tanto por razones religiosas como físicas. ${ }^{13}$

\section{Un nuevo humanismo}

Serían personalidades como Alegre o Clavijero quienes permitirían e impulsarían la enseñanza de un nuevo sistema del mundo en América. Es por ello que Elías Trabulse, hablando del apogeo del movimiento ilustrado del siglo XVIII en Nueva España, nos dice:

Es indudable que esto no hubiera sido posible sin la labor de apertura iniciada por la Compañía de Jesús en los treinta o cuarenta años anteriores a su expulsión. Fue con ellos que la Ilustración europea penetró en la América española en general y en México en particular, con aquellas modalidades que caracterizaron al movimiento ilustrado americano y que lo hacen diferente del europeo. ${ }^{14}$

Lo interesante es que tal apertura no sólo provocaría cierta ruptura con la mera tradición, sino que permitiría el desarrollo de una reevaluación de la misma y con ella el surgimiento de un nuevo modo de entender el cosmos, no sólo en su sentido físico, sino también en su sentido social y político. Estamos ante el surgimiento de un nuevo humanismo:

El humanismo europeo fue, en mucho, una respuesta a la escolástica decadente sobre el tema del hombre; por el contrario, el humanismo mexicano se debe a escolásticos abiertos a la modernidad. Es consecuencia de un proceso de racionalidad que responde a una situación concreta $[\ldots]$ Es, el mexicano, un humanismo con relación a lo social

\footnotetext{
13 Ibid., p. 43.
}

${ }^{14}$ Ibid., p. 39. 
concreto que tiene, entre varios fundamentos y bases [...] al derecho natural. $^{15}$

Este humanismo novohispano, distinto del de la escolástica - pero pendiente de ella- y distinto del humanismo moderno europeo - pero consciente de él- tiene, a juicio de Rovira, dos connotaciones fundamentales:

[...] en este humanismo de los jesuitas mexicanos del siglo XVIII pueden distinguirse dos connotaciones: una [...] caracterizada por una marcada dirección social y política que plantea la necesidad de una transformación en el pensamiento y en la práctica; otra, en la que lo propuesto nos conduce a las bases filosófico-teológicas del humanismo al que venimos refiriéndonos. ${ }^{16}$

Ésta es, pues, la situación en la que se encontraban los jesuitas del XVIII. Entre eclecticismos, multiculturalismos $-\mathrm{y} / \mathrm{o}$ interculturalismos-, aperturas a la modernidad -en el mundo físico y eventualmente en el social y político-, una tensa relación con la Corona española, el destierro a Italia -y el recuerdo de lo novohispano desde allí- y al surgimiento de un nuevo humanismo nacen las Instituciones teológicas de Francisco Javier Alegre.

\section{Francisco Javier Alegre: un humanista destacado}

Francisco Javier Alegre fue uno de los filósofos jesuitas más importantes del siglo XVIII. Así lo reconoce Arnold Kerson:

Francisco Javier Alegre (1729-1788) pertenece a aquel grupo de jesuitas mexicanos del siglo XVIII, que incluye a autores [...] distinguidos [...] De todo el grupo, Alegre, historiador de su orden, gran teólogo, poeta y perceptista literario y destacada figura del humanismo mexicano del siglo XVIII, fue probablemente el más versátil e ilustrado, y sin lugar a dudas, el mejor latinista. ${ }^{17}$

Instituciones teológicas fue escrita por Alegre con el propósito de compilar sus apuntes de clase estando exiliado en Bolonia. Él dio particular importancia

${ }^{15}$ M. del C. Rovira Gaspar, "Filosofía y humanismo", en op. cit., pp. 57-58.

${ }^{16}$ Ibid., p. 59.

${ }^{17}$ Arnold L. Kerson, "Francisco Javier Alegre, humanista mexicano del siglo XVIII, y la esclavitud", en Actas del XII Congreso de la Asociación Internacional de Hispanistas, 21-26 de agosto de 1995. Versión electrónica en cvc.cervantes.es/literatura/aih/pdf/12/ aih_12_6_044.pdf, p. 308. [Consulta: 11 de diciembre de 2012.] 
a esta obra: "Las Instituciones teológicas, o sea, Los principios de la teología, un intenso y extenso estudio en siete volúmenes, es la obra magna de Alegre, la que más tiempo y esfuerzo le costó, y la que él consideró más sustancial y más digna de su atención y de su interés [...]"18

Instituciones teológicas no sólo fue una compilación de sus clases sino también una compilación de la filosofía desarrollada por este gran pensador. Pero ¿cuáles fueron las condiciones de esta filosofía? y ¿de dónde se deriva este desarrollo?

El primer paso para comprender la estructura de pensamiento desde la que se deriva el razonamiento de Alegre requiere notar su gran habilidad para las lenguas. Será este dominio el que le permitirá acceder de manera directa al pensamiento de los principales autores clásicos y contemporáneos: "Alegre dominaba el hebreo, griego, latín, náhuatl, francés, inglés e italiano, lenguas que le permitieron el acceso directo a las fuentes primarias de pensadores de la envergadura de Homero, Platón, Aristóteles, los padres de la Iglesia griegos y latinos, Tomás de Aquino, Descartes, Leibniz, Bacon, Gassendi, etcétera". ${ }^{19}$

La principal influencia de Alegre será la del pensamiento escolástico. Alegre es consciente de la tradición griega, en específico, de la tradición aristotélica. Si bien la influencia de Aristóteles y de Tomás de Aquino deben ser un supuesto previo al hablar de los filósofos novohispanos, no excluye la influencia del pensamiento moderno -como he mostrado arriba. En este caso, la modernidad adquirirá la forma de un re-pensamiento de las fuentes clásicas cara al pensamiento contemporáneo:

La modernización alegrina de Instituciones teológicas consiste en la vuelta a las fuentes directas de Aristóteles y Tomás de Aquino; un amplio cultivo de las letras clásicas; el estudio de las filosofías modernas, como la de Bacon y Descartes; la separación metódica de las ciencias particulares frente a la filosofía, y el rescate de la cultura mexicana autóctona. ${ }^{20}$

El pensamiento de Alegre dista mucho de ser un mero pensamiento escolástico limitado a las cuestiones abiertas por esta tradición; más que eso se muestra como una reflexión sobre los pasos del pensamiento escolástico que, tratando de ser fiel a los principios de ésta, asume y discute las ideas de los diversos pensadores de la época.

${ }^{18}$ Idem.

${ }^{19}$ Virginia Aspe Armella, "Criollismo y escolástica en la obra Instituciones teológicas de Francisco Javier Alegre”, en M. del C. Rovira Gaspar y C. Ponce Hernández, comps., op. cit., p. 11.

${ }^{20}$ Ibid., p. 14. 
La influencia del pensamiento aristotélico y tomista se expresará en uno de los principios de la reflexión alegrina: la noción de recta razón. Éste es el punto central del que se deriva la estructura de pensamiento que influirá las reflexiones de Alegre respecto a la justicia.

Su definición acerca de la ley se basa en la $S$. Th., I-II, q. 90, a.3, c.1. Concepto de ley cuya base es la recta razón y no los pactos o acuerdos sociales voluntarios al modo de un Hobbes.

La fuerza de su argumentación surge de la consideración de los primeros principios del orden práctico que justifica el fin de la naturaleza social del hombre: el bien común de la República que no surge de un acto voluntario entre los hombres - el consenso-, sino por la recta ratio agibilum con relación al fin intrínsecamente social. ${ }^{21}$

Que el bien común y la ley no se basen en la voluntad no quiere decir que no exista una parte voluntaria en la explicitación de los mismos. Lo que Aspe señala en este punto es el hecho de que tales leyes y tal bien común son una expresión de una ley natural -una manera de explicitarla. De esta ley natural se deriva la noción de igualdad entre los individuos que se expresa en el derecho de gentes que será el punto de partida de las reflexiones políticas de Alegre:

Para Alegre, como para muchos de los antiguos escolásticos, el derecho de gentes no es un derecho positivo o convencional, sus preceptos son "a manera de conclusiones inmediatas o casi inmediatas de la ley natural”. De esta igualdad ontológica y de derechos del género humano arranca la filosofía política alegrina: "La autoridad se funda en la naturaleza social del hombre pero su origen próximo es el consentimiento de la comunidad".

El derecho de gentes se basa en la natural necesidad humana y en su equidad natural, y sólo a partir del entramado social pueden establecerse jerarquías entre los hombres. ${ }^{22}$

Con base en el principio de la recta razón y la noción de equidad que se explicita en el derecho de gentes, Alegre muestra una manera en que la dinámica social, natural del hombre, debería expresarse:

El Estado o sociedad civil promueve el bien de la comunidad como fin último [...] La sociedad civil establece un acuerdo voluntario para

${ }^{21}$ Ibid., p. 16.

${ }^{22}$ Ibid., p. 15. 
designar a la autoridad [...] Lo natural es que haya una autoridad civil; lo voluntario es cuál autoridad sea elegida, pues no podría garantizarse la equidad real de los hombres si no se explicitaran positivamente los derechos. [...]

Los hombres establecen positivamente que todo lo referente al bien común sea decretado por el común sufragio del pueblo; establecen acuerdos voluntarios en torno a los medios para el buen gobierno. ${ }^{23}$

Estos son los principios estructurales que más adelante se expresarán en la defensa de la meritocracia de Francisco Javier Alegre. Por medio de ella se garantizaría cierto tipo de equidad basada en la proporción geométrica o justicia distributiva.

Respecto a la influencia de Locke en Alegre, siendo éste uno de los principales representantes del humanismo jesuita del siglo XVIII, es claro que tuvo que haber conocido la obra del inglés. Se sabe que Alegre dominaba el idioma inglés, así que pudo acceder a estas obras, ya sea por vía directa: "La filosofía política de Locke contenida en sus famosos Dos tratados sobre el gobierno civil, que conocerían una extraordinaria difusión, como toda su filosofía, en la Francia y Europa del siglo XVIII a través de los autores franceses [...]"24

O bien, por medio de los autores franceses de la época:

Tradicionalmente, los historiadores mexicanos nos hemos empeñado en explicar las expresiones ilustradas de nuestros intelectuales en esa época, a la luz de su relación con el movimiento ilustrado francés. [...] quienes integraron el espacio público ilustrado en la Nueva España formaron parte de redes de intelectuales transoceánicas que abarcaban toda Europa $[\ldots]$ a través de esos vínculos, los novohispanos tuvieron, además del impacto de los intelectuales españoles y franceses, una influencia sustantiva de otras expresiones europeas de la Ilustración. ${ }^{25}$

O quizás por otra vía, pues las primeras ediciones del Ensayo sobre la sociedad civil en italiano que se pueden encontrar en el fondo de documentos antiguos de la Universidad de Bolonia datan de $1755,{ }^{26}$ la expulsión de los

${ }^{23}$ Ibid., p. 17.

${ }^{24}$ Francisco Baciero Ruiz, "Francisco Suárez como gozne entre la filosofía política medieval y John Locke", en Repositorio documental de la Universidad de Salamanca, p. 1. Versión electrónica: gredos.usal.es/jspui/handle/10366/113178. [Consulta: 10 de octubre de 2014.]

${ }^{25}$ M. C. Torales Pacheco, "Apuntes para el estudio de la presencia de la Ilustración alemana en México”, en op. cit., p. 123.

${ }^{26}$ Fondo de documentos antiguos de la Universidad de Bolonia: sol.unibo.it/SebinaOpac/Opac. [Consulta: 11 de diciembre de 2012.] 
jesuitas fue en 1767, e Instituciones teológicas fue publicada en 1788; Alegre bien pudo tener acceso a las obras de Locke en Bolonia al tiempo que escribía su obra más importante.

\section{John Locke}

\section{Locke y la escolástica}

Ahora bien, en lo que respecta a la estructura de pensamiento de John Locke, quiero enfatizar, en primer lugar, que si bien es cierto que formó parte de los pensadores del proyecto moderno, su educación da evidencias de su conocimiento de las filosofías escolástica y griega -aun cuando en algunos puntos se separe de éstas: "En el tiempo que estudió Locke en Oxford imperaba aún el escolasticismo, y su influencia, como han demostrado Gibson y Krakowski, es muy importante en él". ${ }^{27}$

A esta afirmación de Luis Rodríguez Aranda se suma la siguiente observación de Thomas P. Peardon: "Estaba familiarizado con la gran tradición medieval de la política a la cual tanto le debe la libertad moderna - la tradición de que el gobierno emana de la comunidad, está subordinado a la ley, y debe procurar el bienestar popular". 28

La misma idea es sostenida por Francisco Baciero, quien ha encontrado similitudes entre el pensamiento lockeano y el de Francisco Suárez: ${ }^{29}$ “[...] las doctrinas políticas lockeanas contenidas en los dos Tratados sobre el gobierno civil, parezcan resumir en muy buena medida las de un escolástico medieval [...]"30 E incluso nos reporta algún otro testimonio en este sentido: "[...] el eminente economista A. Schumpeter, en su magna obra sobre la Historia del análisis económico caracterizó ya en su día a Locke y a otros autores de su generación como "escolásticos protestantes" [...]"31

${ }^{27}$ Luis Rodríguez Aranda, "Introducción”, en John Locke, Ensayo sobre el gobierno civil. Trad. de Amando Lázaro Ros. Barcelona, Orbis, 1985, p. 11.

28 Thomas P. Peardon, "Introducción", en Segundo tratado de gobierno. Buenos Aires, Ágora, 1959, p. 13.

${ }^{29}$ El estudio de Baciero respecto a este asunto es muy interesante, sin embargo, debido a que excede los propósitos de este trabajo no entraré a fondo en las especificaciones que éste hace respecto a Locke.

${ }^{30}$ F. Baciero Ruiz, "Francisco Suárez como gozne entre la filosofía política medieval y John Locke”, en op. cit., p. 19.

${ }^{31}$ Ibid., p. 2 , n. 2. 
Locke y la ley natural

Tomando en cuenta su familiaridad y empatía con el pensamiento medieval, no es raro que Locke sea visto por muchos como el continuador de una tradición clásica en política. En específico por su recurso a la noción de ley natural:

Esta ley de la naturaleza, básica en la teoría política de Locke, es conocida en la historia de la filosofía. Encontramos rastros de ella en Aristóteles, que habló de una ley positiva y de otra universal y anterior a aquélla. [...] En la Edad Media pervive en el pensamiento de los filósofos cristianos. En De regimine principum, Santo Tomás sostiene que el exercitium de la autoridad reside en el pueblo y que es éste el que la confiere. El gobierno lo instituye la comunidad y puede derrocarlo si se convierte en tiránico. [...]

John Locke continúa, pues, una brillante tradición. Reconocida la existencia de una ley natural y de un estado de naturaleza, el gobierno se forma mediante un voluntario sometimiento de las libertades individuales a un poder superior para que éste las proteja. ${ }^{32}$

Este reconocimiento de una ley natural es determinante en el pensamiento de Locke. Será en función de esta ley natural que en los hombres podrá existir la capacidad de adquirir el criterio correcto - recta ratio- para determinar los límites del actuar político: "El concepto de la ley de la naturaleza es fundamental en Locke [...] Para él era realmente una regla objetiva y una medida que emanaba de Dios y averiguables por parte de la razón humana. Proveía una prueba o criterio por el que las instituciones y el comportamiento políticos podían ser limitados y juzgados". 33

\section{Locke y los absolutismos}

Esta ley de la naturaleza que puede expresarse al modo de un criterio que permite percatarse de los límites de las instituciones y los comportamientos políticos es también el garante de la igualdad entre los individuos: "[...] la mayor lección que John Locke aprendió de la ley de la naturaleza fue que aun antes de que existiera gobierno los hombres eran libres, independientes e iguales en el disfrute de inalienables derechos, siendo los principales entre ellos la vida, la libertad y la propiedad". ${ }^{34}$

\footnotetext{
${ }^{32}$ L. Rodríguez Aranda, "Introducción", en op. cit., p. 15.

33 Th. P. Peardon, "Introducción", en op. cit., p. 15.

${ }^{34}$ Idem.
} 
A la luz de esta inferencia derivada del principio de la ley de la naturaleza es claro el propósito que inspira la obra política de Locke -al menos el Ensayo sobre el gobierno civil o The Second Treatise of Goverment-y su oposición a los sistemas absolutistas: "El punto fundamental sobre el que versa el segundo tratado es que el gobierno debe ejercitarse con el consentimiento de los gobernados. El hombre o gobierno que ha perdido la confianza de su pueblo carece de derecho para gobernarlo. El gobierno es creación del pueblo, y el pueblo lo mantiene para asegurar su propio bien". 35

Un gobierno que no sea aceptado por el pueblo es un gobierno que viola la libertad del mismo, porque pasa por alto el principio de equidad en el que se basa la elección de un dirigente. El pueblo elige al dirigente porque todos somos iguales y tenemos capacidad de decisión; evitar que los individuos ejerciten plenamente esta capacidad de decisión no sólo será pasar por alto la igualdad entre las personas, sino también un modo de truncar sus libertades.

Es bajo esta interpretación que para Locke un gobierno absolutista, o un gobierno patriarcal, que considere a los individuos meritorios de un cargo en función de su posición social o su linaje, no puede ostentarse como modelo de gobierno que garantice el respeto a la libertad e igualdad de los gobernados:

Locke dirige sus escritos políticos contra dos líneas de argumentación absolutista. La primera era la patriarcal teoría de la monarquía de derecho divino expuesta por sir Robert Filmer [...] Filmer había argumentado que los reyes eran o debían ser considerados como directos sucesores de Adán [...] El Segundo tratado estuvo dirigido, aunque sin decirlo específicamente, contra la línea de argumentación en pro del absolutismo presente en el Leviatán, de Hobbes, en $1651 .^{36}$

De este modo, aunque la filosofía de Locke no necesariamente da el paso a una meritocracia -como sí lo hace Alegre-, se opone a los absolutismos y a la distribución de cargos según parentescos o posiciones sociales.

\section{La influencia de John Locke en el tratamiento de la justicia en el libro VI, proposición XIX de Instituciones teológicas de Francisco Javier Alegre}

Hasta aquí he tratado de mostrar, en esta exposición de los principios estructurales desde los que se derivan los pensamientos de Locke y Alegre, que el

\footnotetext{
35 L. Rodríguez Aranda, "Introducción", en op. cit., p. 14.
}

36 Th. P. Peardon, "Introducción”, en op. cit., pp. 12-13. 
punto de partida de las reflexiones filosófico-políticas de ambos pensadores es la noción de ley natural. En específico, una noción de ley natural tomada del pensamiento escolástico.

\section{El proyecto de Locke}

La argumentación de Alegre respecto a la justicia rescata de Aristóteles dos puntos muy simples: $a$ ) la metodología para hablar de la justicia a partir de la injusticia y $b$ ) la distinción entre justicia geométrica y justicia aritmética, que en el caso de Alegre se denominan: justicia distributiva y justicia conmutativa, siguiendo con la tradición tomista. Esta división corresponde a la división aristotélica entre justicia general y justicia particular. Aquí sigue puntualmente la noción de Aristóteles de justicia. Lo mismo sucede en las divisiones de la justicia particular: "[...] existen dos especies de justicia particular, la distributiva y la conmutativa [...] La consideración de las personas según su posición se opone a la justicia distributiva, pues la igualdad de la justicia distributiva consiste en esto: que sean conferidas diversas cosas a diversas personas de acuerdo con la proporción de su mérito [...]"37

Lo que quiero enfatizar de este fragmento es la expresión "la consideración de las personas según su posición". Claramente, Alegre está haciendo una crítica a la distribución de cargos públicos - hecho que se constata en los ejemplos que usa- desde una consideración de linaje o clase social; en cambio propone, como Aristóteles, tomar en cuenta el mérito: “[...] por ejemplo: la consanguinidad hace digno a alguien para algo, como heredar el patrimonio, pero no para esto, para serle conferida la prelación eclesiástica [...] la consideración de las personas según su posición se opone a la justicia distributiva en aquello que se realiza fuera de la debida proporción". ${ }^{38}$

En este punto, Alegre está siguiendo la pista que se deriva de la noción de libertad de Locke. La autoridad de una persona justificada en un cierto linaje es ilegítima por el simple hecho de que nadie puede imponerse como un poder absoluto por naturaleza, a menos que sea por convenio de la población -convenio que según Alegre debería expresarse en la consideración del mérito-, porque todos hemos nacido libres e iguales. Así lo explica Locke en el primer capítulo de su Ensayo sobre el gobierno civil:

Adán no tenía, como se pretende por alguien, ni por derecho natural de paternidad, ni por la atribución positiva echa por Dios, una autoridad de esa clase sobre sus hijos, ni semejante dominio sobre el mundo.

${ }^{37}$ Francisco Javier Alegre, "Instituciones teológicas", en M. del C. Rovira Gaspar y C. Ponce Hernández, comps., op. cit., $₫$ 2, p. 131. Las cursivas son de la edición.

${ }^{38}$ Ibid., \& 2, p. 133. 
Aun admitiendo que él lo hubiese tenido, sus herederos no poseían ese derecho.

Aun admitiendo que sus herederos lo tuviesen, no habría sido posible fijar con absoluta certeza a quién correspondía el derecho de sucesión.

[...] no existe entre las razas de la humanidad ni entre las familias de la Tierra pretensión fundada de que una de ellas sea la casa dinástica más antigua y que a ella corresponda el derecho de sucesión [...]

[...] será absolutamente preciso encontrar otro origen para los gobiernos, otra fuente para el poder político y otro medio para designar y saber cuáles son las personas en quienes recae $[\ldots]^{39}$

Ésta es la reflexión que motiva el pensamiento lockeano: la búsqueda de un nuevo modo de establecer el origen del gobierno fuera de la consideración de las personas según su posición, es decir, según su linaje, su clase o su riqueza.

Alegre sigue esa pista, le da una respuesta y una aplicación; completa la cuestión abierta por Locke. Al negar la legitimidad de los gobiernos fundados en linajes, Locke deja la puerta abierta a la búsqueda de un nuevo modo para designar a las personas a las que corresponde el poder político. Alegre se proclama al respecto diciendo que el único tipo de desigualdad admisible - por tanto, el único criterio de distinción- debe ser la que se derive de la justicia distributiva, en específico, la consideración de la persona según su mérito:

[...] puesto que el juicio es el acto de la justicia en la medida que un juez devuelve a igualdad las cosas que parecen hacer iniquidad opuesta y la consideración de las personas por su posición induce cierta iniquidad en cuanto que se tributa a la persona alguna cosa fuera de la proporción, a la cual atiende la justicia, es manifiesto que el juicio se corrompe por la consideración de las personas por su posición. ${ }^{40}$

Detrás de la crítica a la "consideración de las personas según su posición" se encuentra un afán por respetar el principio de igualdad. Este testimonio reafirma la coincidencia de Alegre con Locke: es en virtud de la igualdad-que para Alegre debe ser preservada por la justicia- que debe evitarse la consideración de los individuos según su linaje, su riqueza, etcétera. Sin embargo, Alegre da un paso más allá de su empatía con el pensamiento lockeano; Alegre propone al mérito como criterio de distinción.

${ }^{39}$ J. Locke, Ensayo sobre el gobierno civil, \$\$ 1-4, p. 23.

${ }^{40}$ F. J. Alegre, "Instituciones teológicas", en op. cit., \5, p. 137. 


\section{La propiedad}

Persona conjunta

Locke usa la palabra propiedad en un sentido lógico, es decir, como aquello que se da siempre en el ser humano, pero que no lo define. Para Locke ese sentido de propiedad está determinado por la ley natural que ya existía en el estado de naturaleza del hombre: "El estado natural tiene una ley natural por la que se gobierna, y esa ley obliga a todos. La razón, que coincide con esa ley, enseña a cuantos seres humanos quieren consultarla que, siendo iguales e independientes, nadie debe dañar a otro en su vida, su salud, libertad o posesión. [...]"41

Como mostré arriba, la ley natural es parte del mobiliario conceptual de Alegre; sin embargo, supone ciertas distinciones con el modo en que este concepto es utilizado en el pensamiento lockeano. Así, el tema de la propiedad encaja con el pensamiento de Alegre aunque de un modo distinto. En Alegre la propiedad toma las formas de la propia persona, de la persona conjunta y de la pertenencia. La primera, atendería a lo que en Locke se encuentra como la vida, la salud y la libertad; la segunda, sería un correlato de la posesión, y la tercera, referiría a la posesión, pero en su carácter de posesión de ciertos bienes. Tanto la persona conjunta como la persona propia componen la dimensión personal de un sujeto - sin ser por ello, todo lo que una persona es. Del mismo modo, la propiedad se da siempre en el individuo pero no lo define, pues no es necesariamente todo lo que el sujeto es. Es por ello que tanto el daño a la persona propia como a la persona conjunta son considerados por Alegre como daños reales a la persona -si bien, no específicamente el mismo daño.

En cuanto a la pertenencia, ciertamente, si uno toma ocultamente la de otro [...] en cuanto a la propia persona, acontece ya sea en cuanto a su consistencia misma, ya sea en cuanto a su dignidad [...] alguien es lesionado en la persona conjunta: en la esposa [...] y en el siervo [...] la razón es la misma acerca de otras personas conjuntas $[\ldots]^{42}$

Si bien Locke no considera directamente a la esposa, a los hijos o al esclavo como bienes, adquieren cierta dimensión de propiedad. La esposa adquiere esa dimensión por medio de un pacto voluntario: "La sociedad conyugal se establece por un pacto voluntario entre el hombre y la mujer. Aunque esa sociedad viene a ser, principalmente, una unión carnal y el derecho de cada

${ }^{41}$ J. Locke, op. cit., $\$ 6$, p. 26.

${ }^{42}$ F. J. Alegre, "Instituciones teológicas", en op. cit., \& 6, pp. 137 y 139. 
uno de los cónyuges sobre el cuerpo del otro, hasta donde ello es necesario para su finalidad principal, que es la procreación [...]"43

Sólo en virtud de la unión carnal y de la procreación y sus consecuencias -a saber: la crianza de los hijos- puede considerarse a la mujer como parte de la propiedad del hombre. Hay que resaltar que para Locke este tipo de propiedad supone, a la vez, un grupo de obligaciones que deben cumplirse para honrarla. Por su parte, el hijo se considera como parte de la propiedad de los padres sólo hasta que alcanza su mayoría de edad, es decir, hasta que alcanza un pleno uso de su razón:

[...] la autoridad que poseen los padres sobre los hijos se deriva de la obligación en que están de cuidar de ellos mientras se encuentran en el estado imperfecto, propio de la niñez. [...] lo que incumbe a los padres, es dirigir las acciones de sus todavía ignorantes menores de edad, hasta que la razón haya adquirido su desarrollo y los libre así de semejante tarea. ${ }^{44}$

En este sentido se da la propiedad de los padres sobre los hijos. Como se ve, este tipo de propiedades suponen cierto tipo de obligaciones a la par. Del mismo modo sucede con la esclavitud: "Tal es la auténtica condición de la esclavitud; ésta no es sino la prolongación de un estado de guerra entre un vencedor legítimo y un cautivo. En efecto, si se realiza entre ellos un acuerdo y convienen en limitar por un lado el poder, y por el otro la obediencia, el estado de guerra y la esclavitud habrán cesado mientras subsista el contrato [...]"45

En el caso de la esclavitud, el siervo se somete a su señor por medio de un previo estado de guerra en el que, en virtud de la defensa de su propia vida, un individuo logra dominar a otro. Como derivado viene un acuerdo entre ambos. Sin embargo, ese acuerdo no puede tener como parte a la propia vida, pues ningún sujeto es dueño de su propia vida.

El punto a definir aquí es la manera en que la propiedad se da en el esclavo, el hijo y la esposa. El principal problema para ese propósito está en definir cómo puede alguien que tiene propiedades ser propiedad de alguien más. La respuesta de Locke es que por medio de la renuncia voluntaria de cierta parte de las facultades que se tienen sobre uno mismo - como en los casos del esclavo y de la esposa- o por la falta de esas facultades - como en el caso del hijo- se puede ser parte de la propiedad de otro - en la medida en que lo marcan las relaciones bajo las cuales se genera el dominio.

\footnotetext{
${ }^{43}$ J. Locke, op. cit., $₫ 78$, p. 65.

${ }^{44}$ Ibid., $\ 58$, p. 53.

45 Ibid., \ 23, p. 37.
} 
Pertenencia

Tomando esto en consideración, los conceptos de persona propia y persona conjunta son compatibles con la noción de propiedad de Locke. En lo que respecta a lo que Alegre entiende por pertenencia parece haber una diferencia con el pensamiento lockeano; al parecer, Alegre entiende el daño en la pertenencia como un daño real, pero no necesariamente como un daño directo en alguna dimensión de la persona.

Persona propia: la vida

\section{El suicidio}

Un punto en el que parecen converger Locke y Alegre es en la propia vida -que para Alegre correspondería a parte de la dimensión de la propia persona. En ambos casos hay una valoración de la vida que depende de Dios y, por ello, hay cierta incapacidad para tener absoluto dominio sobre la propia vida - como mostré en el fragmento referente a la esclavitud en Locke. "[...] nadie es juez de sí mismo: consecuentemente, no está permitido, incluso a quien tiene pública autoridad, suicidarse por cualquier pecado o cualquier causa [...]"46

Alegre pone la restricción al suicidio en virtud del juicio. Con una referencia al hecho de que el verdadero juez de la vida humana ha de ser Dios, Alegre muestra un límite para el dominio que uno puede tener de la vida como parte de la propia persona. Aquí hay que destacar la coincidencia con Locke en el hecho de considerar a la vida como algo propio, es decir, como un algo que se posee -aunque en ambos casos se posea de modo limitado. Más allá de considerarlo como algo que está dado en un hombre, Alegre, al igual que Locke, considera a la vida como una propiedad.

En el caso de Locke el límite al suicidio y con ello el límite del dominio de la vida como propiedad viene dado por el hecho de que Dios es quien ha dado vida al hombre y, como tal, es el único con la potestad para quitársela: "Dios ha dado el mundo a los hombres en común; pero puesto que se lo dio para beneficio suyo y para que sacasen del mismo la mayor cantidad posible de ventajas para su vida [...]" 47

Para Locke, la finalidad que Dios persigue detrás de la creación del mundo es el bienestar de la vida humana, por lo mismo ha dado una ley natural que muestra al hombre como libre. Sin embargo, esta libertad que implica el dominio de su propia vida tiene como límite la medida en la que el hombre es dueño de su vida frente a la medida en la que Dios es dueño de la vida del

${ }^{46}$ F. J. Alegre, "Instituciones teológicas", en op. cit., $₫ 8$, p. 141.

${ }^{47}$ J. Locke, op. cit., \33, p. 41. 
hombre: "[...] ningún hombre puede ceder mediante un acuerdo a otro aquello que él no lleva en sí mismo, es decir, el poder de disponer de su propia vida". ${ }^{48}$

Este límite viene dado por el sentido lógico de la palabra propiedad, no es algo que sea esencial sino algo que se da siempre y no es definitorio. La vida no le es esencial al hombre porque la vida le viene dada por Dios; al mismo tiempo, su vida es parte de su propiedad por la misma causa. Me explico: la vida le viene dada al hombre por Dios, en ese sentido el hombre no es dueño de su propia vida porque sólo podría disponer de ella absolutamente si se la hubiese causado, pero, dado que no se la ha causado él mismo, no puede disponer de ella absolutamente. ${ }^{49}$

La misma razón funciona para explicar por qué el hombre no es juez de sí mismo. Dado que el hombre no se ha dado la vida a sí mismo, no conoce de manera absoluta el sentido que ésta tiene y los criterios con los que ha de ser evaluada. Por tanto, no puede juzgar sobre su propia vida. Si alguien puede juzgar sobre su vida, es Dios.

De este modo, aunque por argumentos diferentes y, a la vez, paralelos, Locke y Alegre llegan a la misma conclusión: el hombre está limitado frente a su capacidad de juzgar y decidir sobre su propia vida; su dominio sobre sí mismo es limitado.

\section{La defensa de la vida}

Otro punto en el que Locke y Alegre coinciden respecto a la vida como propiedad de la persona es la defensa de la misma. Ambos admiten que en caso de peligro un hombre puede matar a otro con el afán de proteger su propia vida -incluyendo los bienes que procuren la conservación de la misma.

Es evidente también por qué sería lícito matar al invasor en defensa de la propia vida. Efectivamente, cada uno tiene el derecho de defender su vida [...] lo mismo debe decirse de los familiares más cercanos, como el padre, la madre, la esposa, los hijos. [...] Igualmente debe decirse acerca de la defensa del rey y de cualquier superior o persona pública, y por la defensa de cualquier inocente, incluso de un extraño [...] También la doctrina es la misma en cuanto a la defensa de los bienes que se disponen para la conservación de la vida. ${ }^{50}$

Locke, por su parte, propone que este poder del hombre de defenderse a sí mismo debe reservarse sólo para aquellos casos en que el poder político

${ }^{4}$ Ibid., \ 27, p. 37.

${ }^{49} \mathrm{La}$ misma argumentación funciona, en ambos casos, para impedir la mutilación y el descuido de la integridad del propio cuerpo.

${ }^{50}$ F. J. Alegre, "Instituciones teológicas", en op. cit., $₫ 11$, p. 145. 
no cumpla con su función. En principio, es el gobierno civil quien debe ejecutar las penas que corresponda a una persona que provoque cierto daño, sin embargo, en algunos casos, podría ser lícito que una persona ejecute tal castigo por sí misma:

El hombre según hemos demostrado ya, nace con un título a la perfecta libertad y al disfrute ilimitado de todos los derechos y privilegios de la ley natural. Tiene, pues, por naturaleza, al igual que cualquier otro hombre o cualquier número de hombres que haya en el mundo, no sólo el poder de defender su propiedad, es decir, su vida, su libertad y sus bienes, contra los atropellos y acometidas de los demás; tiene también el poder de juzgar y de castigar los quebrantamientos de esa ley cometidos por todos en el grado que en su convencimiento merece la culpa cometida, pudiendo, incluso, castigarla con la muerte cuando lo odioso de los crímenes cometidos lo exija, en opinión suya. ${ }^{51}$

Como he dicho los familiares cercanos y los esclavos son parte de esta propiedad en cierto sentido. Por lo tanto, la noción de autodefensa que se deriva del pensamiento lockeano no difiere de la noción defendida por Alegre.

La explotación de los recursos dados por la naturaleza para preservar la vida

Otro punto en el que Locke y Alegre coinciden, también referente a la vida como propiedad, es la explotación de los recursos dados por la naturaleza para preservar la vida. En este punto, Alegre se muestra abiertamente en contra de ciertos pensadores modernos. Sin embargo, Locke, al sostener la misma opinión que Alegre, no forma parte de ese grupo de intelectuales a los que Alegre dirige su crítica.

Es evidente, en tercer lugar, por qué sería lícito para los hombres matar a cualesquiera bestias animales y vivientes, cuestión de la cual no sé cómo se librarían aquellos físicos modernos, quienes estiman que las almas de las bestias son espirituales o poseedoras de no sé qué imperfecta razón [...] puesto que las almas de las bestias son formas meramente materiales y no tienen vida racional, por medio de la cual se conduzcan por sí mismas, sino que sus movimientos son conducidos casi siempre por otro cierto impulso natural, es signo de que fueron destinadas por naturaleza a la servidumbre; en consecuencia por la

${ }^{51}$ J. Locke, op. cit., $\int 87$, p. 68. 
justísima ordenación del creador, su vida y muerte están sometidas a nuestros usos... y nadie peca cuando usa las cosas para el fin que están destinadas por su propia naturaleza. ${ }^{52}$

Alegre, echando mano de concepciones escolásticas, explica la situación del hombre frente a los animales. Aunque acepta sin mayor problema la aniquilación de los animales, ésta no ha de ser una aniquilación ilimitada; es una aniquilación en función de la finalidad que cumplen. En función de la preservación de la vida, la aniquilación de los animales es lícita. Sin embargo, esta justificación sirve también como límite. De este modo, cuando la aniquilación de los animales vaya más allá de las funciones que cumple será considerada una práctica ilícita.

[...] aunque ese estado natural sea un estado de libertad, no lo es de licencia; aunque el hombre tenga en semejante estado una libertad sin límites para disponer de su propia persona y de sus propiedades, esa libertad no le confiere derecho de destruirse a sí mismo, ni siquiera a alguna de las criaturas que posee, sino cuando se trata de consagrarla con ello a un uso más noble que el requerido por su simple conservación. ${ }^{53}$

Locke concibe el consumo de los recursos de la naturaleza -incluidos los animales- en función de la finalidad que cumplen para la subsistencia del hombre. Del mismo modo, será esa finalidad el marcador para limitar el modo y la cantidad en que este consumo ha de proceder. Así, en función de la preservación de la vida -vestido, comida, etcétera- es lícito que el hombre use a las criaturas de la naturaleza como mejor le convenga.

\section{El castigo}

El último punto que quiero tocar aquí respecto a lo que Alegre reconoce como persona propia es el sentido en que el daño a la persona propia es lícito -también aplicable a lo que Alegre considera como pertenencia. Este tipo de daño sólo puede llevarse a cabo, de manera estrictamente lícita, por alguien que tenga potestad sobre la persona sancionada. "[...] no es lícito ocasionar daño a alguien, excepto en razón de una pena por la justicia, pero no puede imponer una pena a otro, quien no tiene potestad alguna sobre aquél a quien le es impuesta la pena; luego entonces, nadie recibe lícitamente azotes, excepto por aquél a cuya potestad está sujeto". ${ }^{54}$

\footnotetext{
${ }^{52}$ F. J. Alegre, "Instituciones teológicas", en op. cit., $』 12$, pp. 145 y 147.

53 J. Locke, op. cit., \$6, p. 26.

${ }^{54}$ F. J. Alegre, "Instituciones teológicas", en op. cit., $₫ 15$, p. 151.
} 
Alegre utiliza el mismo argumento para el caso de la mutilación o, incluso, la pena de muerte.

[...] no puede privarse a sí mismo de la vida, ni puede privar la de otro, excepto cuando por algún crimen se hace indigno de ella, así tampoco puede maltratarse a sí mismo ni puede ser maltratado por algún otro en un miembro sano y consistente en su natural disposición, al menos que por algún delito se hiciera indigno, si no de la vida, al menos del uso de algún miembro. 55

Del mismo modo podría suceder con ciertos bienes externos. El ejercicio de estas penas, si bien no es reprobado bajo ciertas circunstancias -como en la defensa de la propia vida en un momento de peligro-, le corresponde primordialmente y con mayor propiedad a quienes tienen la potestad para llevar a cabo estos castigos.

Locke afirma que, aunque el ser humano tendría la posibilidad de ejercer algunos de estos castigos en caso de necesidad - por un peligro inminente, por ejemplo-, la verdadera potestad de castigo le corresponde al poder político. "Entiendo, pues, por poder político el derecho de hacer leyes que estén sancionadas con la pena capital, y, en consecuencia, de las sancionadas con penas menos graves, para la reglamentación y protección de la propiedad [...]"56

Como se ve, la finalidad propia de la institución de tal tipo de poder supone renunciar a la propia facultad de ejercer la fuerza para que alguien que ha sido elegido por consenso se encargue de la protección de la propiedad de quienes se someten a su mando. "[...] el poder político es el que todo los hombres poseen en el estado de naturaleza y al que luego renuncian y ponen en manos de la sociedad, confiándose a los gobernantes que esa sociedad ha establecido para que la rijan, con la misión expresa o tácita de emplearlo para el bien de los miembros de la sociedad y la salvaguardia de sus propiedades". ${ }^{57}$

Tanto Locke como Alegre admiten que, estrictamente hablando, la propiedad del castigo debe atribuirse a las personas que cuentan con la potestad para hacerlo, es decir, con el poder político que se ha establecido. De este modo, la protección de la propia vida y de las finalidades de la sociedad, si bien siguen siendo parte de las facultades que se deben atribuir a un individuo, corresponden primordialmente al poder político.

\footnotetext{
55 Ibid., $₫ 14$, p. 149.

${ }^{56}$ J. Locke, op. cit., $₫ 3$, p. 24.

${ }^{57}$ Ibid., $₫ 171$, p. 115.
} 


\section{Conclusión}

Suele concebirse a la filosofía novohispana como una corriente de pensamiento ajena -o incluso opuesta- a la modernidad. Hasta aquí he tratado de mostrar la clara impronta lockeana en el tratamiento de la justicia de Francisco Javier Alegre. Con ello, la filosofía desarrollada por Alegre no se presenta claramente como una filosofía de transición o moderna o tradicional. La obra de Alegre es sui generis; pocos como él fueron capaces de formular un discurso que, echando mano de la tradición escolástica, siguiera las sugerencias desprendidas del pensamiento moderno.

La erudición de este hombre terminó por convertirlo en un maravilloso filósofo. Alegre demuestra un gran ingenio, una gran comprensión de su momento histórico a nivel global y de las nuevas necesidades que surgen en el mismo. Fue capaz de encuadrar toda esa vanguardia, ingenio y capacidad dentro de un esquema que respetara la tradición escolástica hasta donde le pareció prudente y que, a la vez, atendiera a las necesidades del nuevo mundo moderno que se estaba gestando. La filosofía de Alegre es un ejemplo del eco que tuvo la filosofía moderna dentro de la vida intelectual de los pensadores novohispanos. 